\title{
Unrelated marrow transplantation for adult patients with poor-risk acute lymphoblastic leukemia: strong graft-versus-leukemia effect and risk factors determining outcome
}

Jan J. Cornelissen, Michael Carston, Craig Kollman, Roberta King, Adriaan W. Dekker, Bob Löwenberg, and Claudio Anasetti

Between 1988 and 1999, 127 patients with poor-risk acute lymphoblastic leukemia (ALL) received a matched unrelated donor transplant using marrow procured by National Marrow Donor Program (NMDP) collection centers and sent out to 46 transplant centers worldwide. Poor risk was defined by the presence of the translocations $t(9 ; 22) \quad(n=97)$, or $t(4 ; 11)$ $(n=25)$, or $t(1 ; 19)(n=5)$. Sixty-four patients underwent transplantation in first remission (CR1), 16 in CR2 or CR3, and 47 patients had relapsed ALL or primary induction failure (PIF). Overall survival at 2 years from transplant was $40 \%$ for patients in CR1, $17 \%$ in CR2/3, and $5 \%$ in PIF or relapse. Treatment-related mortality (TRM) and relapse mortality, estimated as competing risk factors, were $54 \%$ and $6 \%$, respectively, in CR1, $75 \%$ and $8 \%$ in $\mathrm{CR} 2 / 3$, and $64 \%$ and $31 \%$ in PIF or relapse. Currently 23 CR 1 patients are alive and free of disease with a median follow-up of 24 months (range, 3-97). Multivariable analysis showed that CR1, shorter interval from diagnosis to transplantation, DRB1 match, negative cytomegalovirus (CMV) serology (patient and donor), and presence of the Philadelphia chromosome, $t(9 ; 22)$, were independently associated with better disease-free survival (DFS). Transplantation in CR and presence of $t(9 ; 22)$ were associated with lower risk of relapse. Shorter interval from diagnosis to transplantation, DRB1-match, negative CMV, higher marrow cell dose, and Karnofsky score of 90 or higher were associated with less TRM. These results indicate that, despite a relatively high TRM, the low relapse rate resulted in a $37 \% \pm 13 \%$ DFS for CR1 patients, comparing favorably to results obtained with chemotherapy alone and matching results following HLA-identical sibling transplantation. (Blood. 2001;97: 1572-1577)

() 2001 by The American Society of Hematology

\section{Introduction}

Long-term disease-free survival (DFS) for adult acute lymphoblastic leukemia (ALL) has only moderately improved during the last 2 decades despite more intensive induction and postinduction therapy and better supportive care facilities. ${ }^{1-3}$ Several characteristics have emerged as high-risk factors in adult ALL, such as high white blood cell (WBC) counts, older age, late complete remission (CR), B-lineage immunophenotype, and chromosomal abnormalities. ${ }^{4-9}$ Recent multicenter studies confirmed that the outcome of patients with Philadelphia $(\mathrm{Ph})$ chromosome-positive $\mathrm{t}(9 ; 22)$ ALL remains invariably poor with a DFS at 2 years of only $10 \%$ to $15 \% .^{5-12}$ The translocation $\mathrm{t}(9 ; 22)$ occurs in approximately $25 \%$ of adult ALL and its incidence increases with age. Other translocations in B-lineage ALL such as $t(4 ; 11)$ and $t(1 ; 19)$ occur less frequently, but may also be associated with a poor prognosis. ${ }^{8,11}$

Although up to $70 \%$ of patients may achieve CR after induction chemotherapy, long-term DFS has remained poor due to a high rate of relapse. Only allogeneic bone marrow transplantation (BMT) applied as consolidation therapy in first remission (CR1) was associated with higher DFS. ${ }^{13-19}$ Retrospectively collected data of HLA-identical sibling BMT in $\mathrm{Ph}^{+}$ALL from the International Bone Marrow Transplant Registry (IBMTR) ${ }^{14}$ suggested that DFS after allogeneic BMT might improve to $38 \%$, which findings were

From the University Hospital Rotterdam/Daniel den Hoed Cancer Center Rotterdam, The Netherlands; University Medical Center, Utrecht, The Netherlands; National Marrow Donor Program, Minneapolis, Minnesota; and Fred Hutchinson Cancer Research Center, Seattle, Washington.

Submitted July 13, 2000; accepted October 27, 2000.

Supported by funding from the National Marrow Donor Program, the Office of Naval Research N00014-93-1-0658, and the Health Resources and Services Administration no. 240-97-0036. Also supported by PO1 grant CA1802, National Institutes of Health, National Cancer Institute, Bethesda, MD. confirmed by the City of Hope group, which showed a DFS of approximately $50 \%$ at 2 years. ${ }^{13,15,16,19}$ However, HLA-identical sibling donors are available for only a limited number of patients. Alternatively, HLA-matched unrelated donors have been used with increasing frequency as allogeneic donors for patients with highrisk acute leukemia. ${ }^{20,21}$ Currently, only limited data are available showing results of unrelated BMT in poor-risk ALL. Here, we report results from 127 transplantations performed between 1988 and 1999 with grafts identified and procured by the National Marrow Donor Program (NMDP) for adult patients with poor-risk ALL. It is shown that outcome in patients in CR1 compares favorably to what can be observed with chemotherapy alone and matches current results with HLA-identical sibling donors.

\section{Patients and methods}

\section{Patients}

The study population consisted of 127 adult patients with poor-risk ALL at 46 transplant centers worldwide, who received marrow transplants facilitated by the NMDP between 1988 and April 1999. Patients, donor, and graft characteristics are shown in Table 1. Poor-risk ALL was defined by the

Reprints: Jan J. Cornelissen, Department of Hematology, University Hospital Rotterdam/Daniel den Hoed Cancer Center, Groene Hilledijk 301, 3075 EA Rotterdam, The Netherlands; e-mail: cornelissen@hemh.azr.nl.

The publication costs of this article were defrayed in part by page charge payment. Therefore, and solely to indicate this fact, this article is hereby marked "advertisement" in accordance with 18 U.S.C. section 1734.

(C) 2001 by The American Society of Hematology 
Table 1. Patient and donor characteristics

\begin{tabular}{|c|c|c|c|c|}
\hline Parameter & $\begin{array}{l}\text { First remission } \\
\qquad(\mathrm{n}=64)\end{array}$ & $\begin{array}{l}\text { 2nd, 3rd remission } \\
\qquad(\mathrm{n}=16)\end{array}$ & $\begin{array}{l}\text { Refractory } \\
(\mathrm{n}=47)\end{array}$ & $P$ value \\
\hline \multicolumn{5}{|l|}{ Median age (y) } \\
\hline Recipient (range) & $31(16-54)$ & $27(17-51)$ & $36(19-51)$ & .22 \\
\hline Donor (range) & $38(22-58)$ & $30(20-47)$ & $35(22-55)$ & .07 \\
\hline \multicolumn{5}{|l|}{ Gender combinations (no. patients) } \\
\hline Recipient male/donor female & 8 & 4 & 5 & \multirow{4}{*}{.40} \\
\hline Recipient male/donor male & 22 & 5 & 16 & \\
\hline Recipient female/donor female & 18 & 6 & 11 & \\
\hline Recipient female/donor male & 16 & 1 & 15 & \\
\hline \multicolumn{5}{|l|}{ ALL } \\
\hline $\mathrm{t}(9 ; 22)$ (no. patients) (percentage) & $48(75 \%)$ & $9(56 \%)$ & $40(85 \%)$ & \multirow{3}{*}{.03} \\
\hline $\mathrm{t}(4 ; 11)$ & $14(22 \%)$ & $4(25 \%)$ & $7(15 \%)$ & \\
\hline$t(1 ; 19)$ & $2(3 \%)$ & $3(19 \%)$ & - & \\
\hline \multicolumn{5}{|l|}{ WBC at diagnosis $\left(\times 10^{9} / \mathrm{L}\right)$} \\
\hline (median, range) & $25(2-631)$ & $10(2-732)$ & $52(2-870)$ & .26 \\
\hline \multicolumn{5}{|l|}{ Percentage of blasts at BMT } \\
\hline (median, range) & $0.4(0-5)$ & $1.2(0-5)$ & $50(0-95)$ & $<.0001$ \\
\hline Time from diagnosis to BMT (mo) & $7(4-19)$ & $19(7-124)$ & $9(4-43)$ & $<.0001$ \\
\hline Time from CR1 to BMT (mo) & $5(0-17)$ & $15(5-124)$ & - & $<.0001$ \\
\hline Karnofsky score 90-100 (percentage) & $53(83 \%)$ & $9(56 \%)$ & $15(32 \%)$ & $<.0001$ \\
\hline \multicolumn{5}{|l|}{ CMV-serology donor/recipient (no. patients) } \\
\hline$+/+$ & 13 & 2 & 14 & \multirow{4}{*}{.56} \\
\hline$-1+$ & 15 & 3 & 13 & \\
\hline$+1-$ & 13 & 5 & 7 & \\
\hline$-/-($ percentage $)$ & $23(36 \%)$ & $6(38 \%)$ & $12(26 \%)$ & \\
\hline \multicolumn{5}{|l|}{ Conditioning regimen (no. patients) (\%) } \\
\hline Сy/TBI & $37(88 \%)\}$ & $6(69 \%) \quad\}$ & $24(72 \%)$ & \\
\hline $\mathrm{Cy} / \mathrm{TBI}+$ Ara-C or VP16 & 19 & 5 & 10 & .18 \\
\hline Other & 8 & 5 & 13 & \\
\hline \multicolumn{5}{|l|}{ Cell dose $\left(\times 10^{8} / \mathrm{kg}\right)$ (range) } \\
\hline TCD & $0.6(0.1-3.6)$ & $0.4(0.1-0.7)$ & $1.0(0.2-1.6)$ & .18 \\
\hline non-TCD & $2.4(0.6-8.1)$ & $3.0(0.2-4.8)$ & $3.1(0.5-6.7)$ & .74 \\
\hline Matched at A, B, DRB1 (no. patients) & 42 & 10 & 26 & .58 \\
\hline Single mismatch at A, B or DR (no. patients) & 22 & 6 & 21 & \\
\hline
\end{tabular}

ALL indicates acute lymphoblastic leukemia; WBC, white blood cell; BMT, bone marrow transplantation; CMV, cytomegalovirus; Cy, cyclophosphamide; TBI, total body irradiation; Ara-C, cytarabin; VP16, etoposide; TCD, T cell depleted.

presence of the translocation $\mathrm{t}(9 ; 22)$, or $\mathrm{t}(4 ; 11)$, or $\mathrm{t}(1 ; 19)$. $\mathrm{Ph}^{+} \mathrm{ALL}$ with $t(9 ; 22)$ represented the majority of patients studied $(n=97,76 \%)$. Diagnosis was based on cytology, karyotype, and immunophenotyping of marrow cells at diagnosis. Patients had received induction and consolidation chemotherapy according to local protocols and proceeded to unrelated donor transplantation according to indications of the individual transplant center. Protocols were approved by local institutional review boards and all patients provided written or oral informed consent.

Characteristics are presented according to remission status at transplant, including 64 patients in CR1, 16 patients in subsequent remission, and 47 patients with primary induction failure (PIF) or relapsed ALL (Table 1). The median age was 32 years for the whole group of patients. Relatively more patients in CR2 or CR3 showed either $\mathrm{t}(4 ; 11)$ or $\mathrm{t}(1 ; 19)(P=.03)$ than patients in CR1. Higher Karnofsky scores were present among patients in CR1, whereas the majority of refractory patients had Karnofsky scores below $90(P<.0001)$. Refractory patients had presented with higher WBC at diagnosis and higher percentage of marrow blasts at the time of BMT. Time from diagnosis to BMT did not differ significantly between patients in CR1 and refractory patients, but patients in $\mathrm{CR} 2$ and $\mathrm{CR} 3$ received their transplant significantly later $(7$ versus 19 months, $P<.0001)$. Survival, DFS, relapse, and treatment-related mortality (TRM) were similar among patients with primary induction failure or relapsed ALL. Therefore, these patients were analyzed as one group of patients with refractory ALL.

\section{Donor marrow and transplantation}

Unrelated donor marrow was provided by 48 donor centers associated with the NMDP. Marrow cells were harvested according to the policies of the
NMDP and transferred by courier to the transplant center. Donor selection was based on HLA serotyping performed for HLA-A and -B and a combination of serotyping and genotyping for HLA-DRB1 according to standard procedures. Donor and recipient pairs were considered matched when identical at HLA-A, -B, and -DRB1 loci. Mismatches included at least one disparity at one of these loci. Graft manipulation was at the discretion of the transplant center. Thirty-three patients received a T-celldepleted (TCD) graft. Methods of T-cell depletion included antibody and complement-mediated T-cell depletion $(n=9)$, elutriation $(n=8)$, immunomagnetic beads $(n=7)$, sheep red blood cell rosetting $(n=6)$, and other $(\mathrm{n}=3)$. Patients receiving TCD marrow were infused with a median number of $0.7 \times 10^{8}$ nucleated cells $(\mathrm{NC}) / \mathrm{kg}$ body weight (recipient) (range, 0.1-3.6). Patients with non-TCD grafts received a median number of $2.8 \times 10^{8} \mathrm{NC} / \mathrm{kg}$ (range, 0.2-8.1). Conditioning for BMT consisted of regimens based on total body irradiation (TBI) in 115 patients. Etoposide or cytarabin was added to the combination TBI and cyclophosphamide in 34 patients. Twelve patients received chemotherapy only. Antilymphocyte globulin (ALG) was added for prevention of rejection in 15 patients. Supportive care measures were according to local protocols.

\section{End points and statistical analysis}

Standard NMDP forms were used for data collection, including pretransplant information, peritransplant events, and short-term and long-term follow-up. Short-term and long-term data were available for 125 patients. End points included engraftment, graft-versus-host disease (GVHD), overall survival (OS), TRM, and relapse. These end points were estimated for 125 patients; 2 CR1 patients were excluded from these analyses because 
no data for these end points were available. However, baseline data and OS were reported for these 2 CR1 patients, so OS could be estimated for 127 patients and Table 1 presents characteristics of 127 patients.

Engraftment was defined as the first of 3 consecutive days when the absolute neutrophil count (ANC) exceeded $0.5 \times 0 \% / \mathrm{L}$. Primary graft failure was defined by a lack of neutrophil engraftment in patients surviving at least 28 days. Secondary graft failure was defined as neutrophil recovery followed by a decline in ANC to below $0.5 \times 10^{9} / \mathrm{L}$ for 3 consecutive days. Acute and chronic GVHD were diagnosed and graded according to consensus criteria. ${ }^{22}$ Chronic GVHD was evaluated among patients who survived at least 100 days after transplantation. Definition of DFS, OS, TRM, and relapse were according to standard criteria. ${ }^{23}$

Results of the study were analyzed as of December 1999. Patient characteristics in the cohorts presented were compared using either the Fisher exact test (for discrete variables) or Wilcoxon rank test (for continuous variables). Table 2 shows the variables that were examined in the univariate and multivariable analyses. In the univariate analysis, OS and DFS were compared using Kaplan-Meier curves. Acute GVHD, chronic GVHD, and relapse were calculated using cumulative incidence, ${ }^{24}$ with death treated as a competing risk. TRM was also calculated using cumulative incidence, with relapse treated as a competing risk. The multivariable analysis for each end point used the Cox proportional hazards model. A significance level of $\alpha=0.05$ was used for all analyses

\section{Results}

\section{Engraftment}

One hundred and eight patients survived beyond the first 28 days after transplantation. Of these 108 patients, 102 showed myeloid engraftment, which was sustained in 90 patients. Nineteen patients died during the first 28 days, of whom 11 patients had already engrafted. Incidences of primary and secondary graft failure were $6 \% \pm 4 \%$ and $7 \% \pm 6 \%$, respectively. Transplantation in CR1 and a lower WBC at diagnosis were associated with a higher incidence of sustained engraftment following multivariable analysis.

Table 2. Parameters considered for the univariate and multivariable models

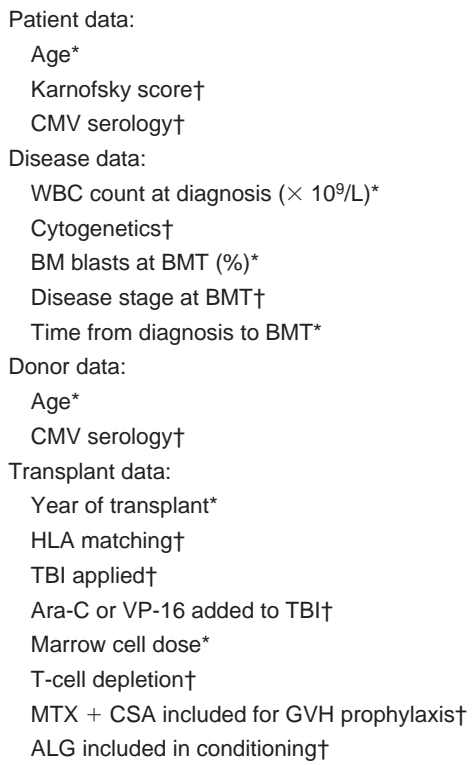

CMV indicates cytomegalovirus; TBI, total body irradiation; Ara-C, cytarabin VP-16, etoposide; MTX + CSA, methotrexate + cyclosporin A; GVH, graft-versushost; ALG, antilymphocyte globulin.

Continuous variables were treated as categorical in the univariate analysis, typically with the variables split at their medians.

Continuous variable.

†Categorical variable.

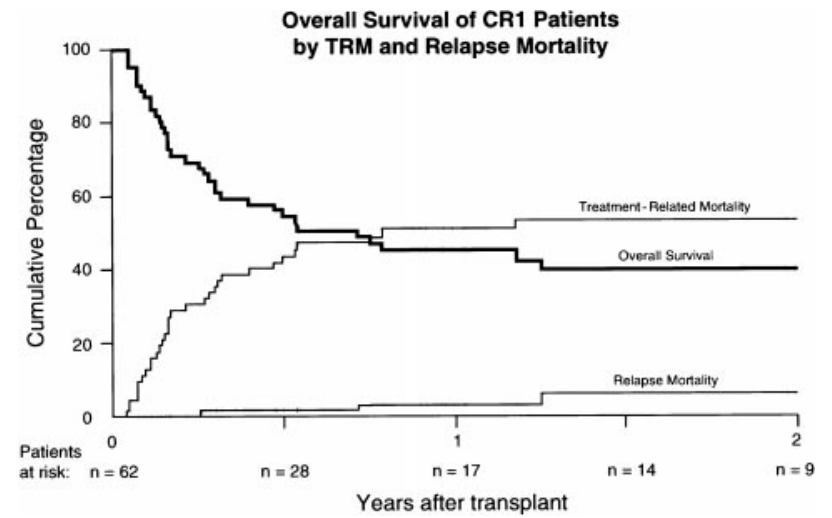

Figure 1. Overall survival in CR1, as determined by the competing risk factors relapse mortality and treatment-related mortality.

\section{OS and DFS}

Overall survival at 2 years from transplantation was $40 \% \pm 13 \%$ for patients undergoing BMT in CR1 and $32 \% \pm 16 \%$ at 4 years. When estimated as competing risk factors for OS, relapse mortality and TRM were $6 \% \pm 7 \%$ and $54 \% \pm 13 \%$, respectively (Figure 1). Currently, 23 CR1 patients are alive and disease free with a median follow-up of 24 months (range, 3-97) and 13 CR1 patients have survived beyond 2 years after BMT. OS was $17 \%$ for patients in CR2/3 and 5\% for patients with refractory ALL at 2 years after BMT. The competing factors relapse mortality and TRM were, respectively, $8 \%$ and $75 \%$ for $\mathrm{CR} 2 / 3$ patients and $31 \%$ and $64 \%$ for refractory patients at 2 years after BMT. Of the 127 patients analyzed, 28 patients are currently alive with a median follow-up of 24 months (range, 3-97).

Overall survival and DFS were most favorably affected by remission status (Figure 2, Table 3). Following multivariable Cox regression analysis, the translocation $\mathrm{t}(9 ; 22)$ was also associated with better DFS, which variable showed no interaction with remission status. In addition, a shorter interval from diagnosis to BMT, matching for A, B, and DRB1, and cytomegalovirus (CMV) seronegativity appeared as independent prognostic factors associated with better DFS. The question whether results had improved in recent years was addressed in univariate and multivariable analysis. DFS was $27 \% \pm 10 \%$ for 77 patients undergoing BMT between 1996 and 1999 and DFS was 13\% $\pm 9 \%$ for 48 patients having transplantation before $1996(P=.07$ by log-rank analysis). However, when forced into the model for multivariable analysis as a continuous variable, no improvement of DFS in recent years could be demonstrated.

Disease-Free Survival

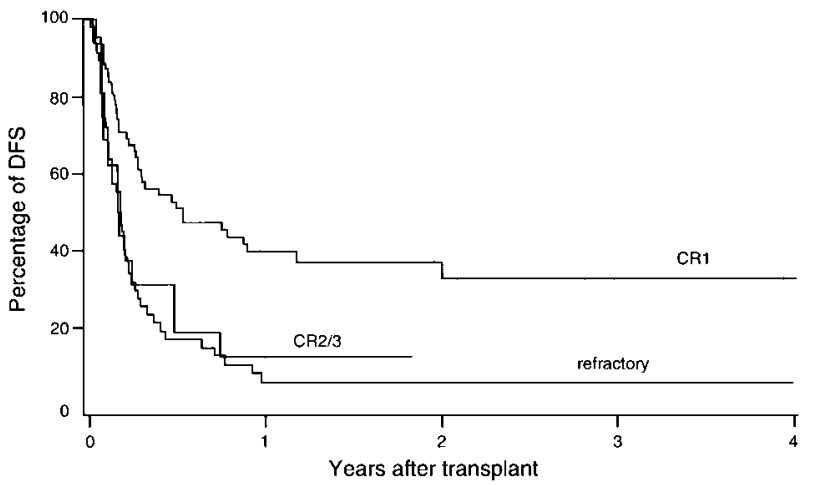

Figure 2. Kaplan-Meier estimate of DFS. The survival difference between CR1 patients versus others was highly significant $(P=.0001)$. 
Table 3. Results of the multivariable analyses

\begin{tabular}{|c|c|c|c|c|c|c|c|c|c|}
\hline \multirow[b]{2}{*}{ Parameter } & \multicolumn{3}{|c|}{ Disease-free survival } & \multicolumn{3}{|c|}{ Treatment-related mortality } & \multicolumn{3}{|c|}{ Relapse } \\
\hline & $\mathrm{RR}$ & $95 \% \mathrm{Cl}$ & $P$ value & $\mathrm{RR}$ & $95 \% \mathrm{Cl}$ & $P$ value & $\mathrm{RR}$ & $95 \% \mathrm{Cl}$ & $P$ value \\
\hline First remission & 1.00 & & NA & 1.00 & & NA & 1.00 & & NA \\
\hline Relapse/PIF & 2.85 & $(1.73-4.68)$ & $<.0001$ & 1.16 & $(0.63-2.13)$ & 0.64 & 9.29 & $(3.23-26.70)$ & $<.0001$ \\
\hline $\mathrm{t}(9 ; 22)$ & 0.49 & $(0.30-0.82)$ & .006 & - & - & - & 0.33 & $(0.11-1.00)$ & .05 \\
\hline Time from diagnosis to $\mathrm{BMT}^{*}$ & 1.33 & $(1.08-1.63)$ & .008 & 1.31 & $(1.05-1.63)$ & 0.009 & - & & \\
\hline CMV serology (pat-, don-) & 0.62 & $(0.38-1.00)$ & .05 & 0.43 & $(0.23-0.80)$ & 0.008 & - & & \\
\hline Karnofsky score $\geq 90$ & - & & - & 0.41 & $(0.23-0.74)$ & 0.003 & - & & \\
\hline \multicolumn{10}{|l|}{ Cell dose: } \\
\hline TCD & - & & - & 0.45 & $(0.18-1.17)$ & 0.10 & - & & \\
\hline non-TCD & - & & - & 0.79 & $(0.64-0.96)$ & 0.02 & - & & \\
\hline
\end{tabular}

$\mathrm{RR}$ indicates relative risk; $\mathrm{Cl}$, confidence interval; NA, not applicable; $\mathrm{CR}$, complete remission; PIF, primary induction failure; $\mathrm{CMV}$, cytomegalovirus; $\mathrm{TCD}$, T-cell depletion. ${ }^{*} \mathrm{RR}$, expressed per year.

\section{Relapse}

The cumulative incidence of relapse was $19 \% \pm 7 \%$ at 4 years after BMT and $13 \% \pm 10 \%$ versus $30 \% \pm 9 \%$ for CR1 and refractory patients, respectively (Figure 3, $P=.001$ ). Twenty-one of a total of 23 relapses had occurred during the first year after BMT. Only one relapse occurred among the 17 patients who received BMT in CR1 and survived for at least 1 year, with a median follow-up of 25 months (range, 12-109). A higher relapse rate was observed in refractory ALL, which appeared as the most significant variable (hazard ratio: 9.29, $P<.0001$, Table 3, Figure 3) affecting relapse by multivariable analysis. In addition, fewer relapses occurred in patients with $\mathrm{Ph}^{+} \mathrm{ALL}$ (hazard ratio: $0.33, P=.05$ ), as compared to patients with $\mathrm{t}(4 ; 11)$ or $\mathrm{t}(1 ; 19)$, which effect appeared independent from remission status. Four patients, including 3 with $\mathrm{t}(9 ; 22)$ ALL, with relapse were treated with donor leukocyte infusions (DLI), and $2 \mathrm{Ph}^{+}$patients achieved a complete response.

\section{TRM}

Cumulative incidence of TRM was $61 \% \pm 9$ at 2 years from transplantation and $54 \% \pm 13 \%$ versus $64 \% \pm 13 \%$ for CR1 and refractory patients, respectively (not significant, Figure 4). The following prognostic factors were associated with less TRM: Karnofsky score 90 or above; HLA matching for A, B, and DRB1; CMV seronegativity; and a higher cell dose for patients receiving non-TCD grafts (Table 3). Age appeared not to be associated with TRM in this group of patients. A shorter interval from diagnosis to BMT predicted for less TRM, which proved independent from remission status. Although TCD was associated with

Relapse

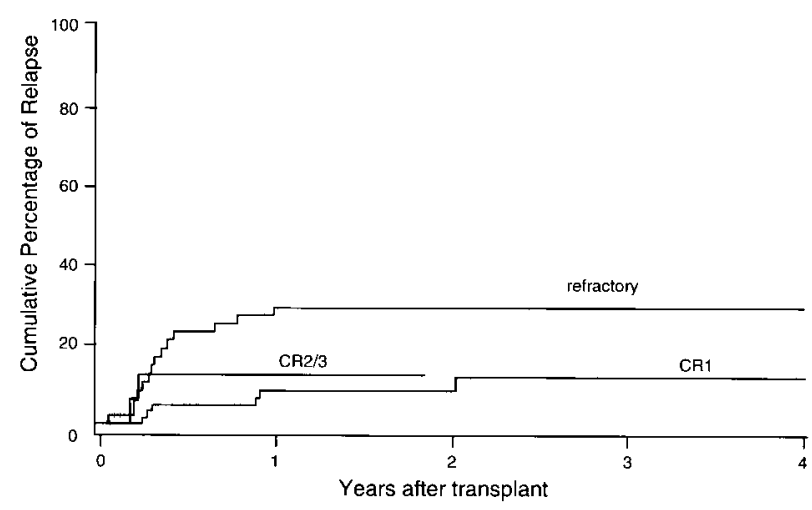

Figure 3. Cumulative incidences of relapse in CR1, CR2/3, and refractory poor-risk ALL following unrelated donor BMT. less GVHD, no reduction of TRM could be observed in patients receiving a TCD graft. Again, year of transplant was evaluated for a possible association with TRM. However, no reduction of TRM could be demonstrated in recent years, when year of transplant was included as 2 categories (below or above the median) in univariate analysis, or as a continuous variable in multivariable analysis. Fifty-seven patients died due to TRM before day 100 after BMT and 25 (44\%) of them had been diagnosed with grade III-IV acute GVHD. Seventeen patients died due to TRM after day 100 and 6 (35\%) of the latter suffered from extensive chronic GVHD. Causes of death included opportunistic infections $(n=25)$, respiratory insufficiency due to lung toxicity/pneumonia without a demonstrated causative infectious etiology $(n=7)$, single organ toxicity (respiratory failure excluded; $n=24)$, GVHD $(n=14)$, hemorrhages $(n=15)$, and graft failure $(n=4)$.

\section{GVHD}

Cumulative incidences of grade II-IV and grade III-IV acute GVHD were $50 \% \pm 8 \%$ and $31 \% \pm 8 \%$ at 100 days after BMT. Higher cumulative incidences at day 100 of grade II-IV of acute GVHD were observed in CMV-seropositive patients $(60 \% \pm 12 \%)$ versus CMVseronegative patients $(40 \% \pm 12 \%)$, in patients receiving non-TCD grafts versus TCD-BMT $(55 \% \pm 10 \%$ and $33 \% \pm 16 \%$, respectively), and in patients receiving TBI-based conditioning versus those conditioned with chemotherapy ( $52 \% \pm 9 \%$ and $25 \% \pm 24 \%$, respectively). In multivariable analysis, a positive CMV serostatus was significantly associated with an increased risk of grade III-IV acute GVHD (relative risk, $4.87 ; P<.0001$ ). Fifty-six patients survived at least 100 days after

Treatment-Related Mortality

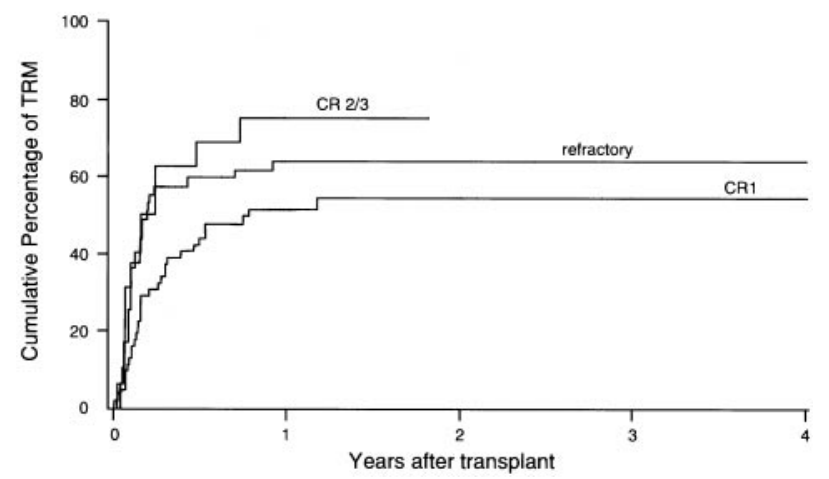

Figure 4. Cumulative incidences of TRM after unrelated donor BMT in poor-risk ALL. Results were not significantly different for CR1, versus CR2/3, versus refractory ALL. 
BMT; the cumulative incidence of chronic extensive GVHD was $48 \% \pm 13 \%$ at 2 years after BMT. Only a higher Karnofsky score favorably affected the incidence of chronic GVHD following multivariable analysis.

\section{Discussion}

In this report, we demonstrate that transplantation of matched unrelated donor marrow results in favorable long-term DFS in adult patients with poor-risk ALL in CR1. DFS observed in patients with PIF or allografted in relapse or beyond CR1 was significantly less, which appeared to be due primarily to transplant-related complications.

Sixty-two patients transplanted in CR1 showed an OS of $40 \% \pm 13 \%$ at 2 years after transplantation, which compares well to results obtained in poor-risk ALL following HLA-identical sibling BMT as reported by single centers and by the IBMTR. ${ }^{13-19}$ In our group of patients, relapse mortality and TRM accounted for loss of OS by $6 \% \pm 7 \%$ and $54 \% \pm 13 \%$, respectively, when estimated as competing risk factors for OS. Only 7 patients developed a relapse and currently 23 CR 1 patients are alive and free of disease with a median follow-up of 24 months. The observed incidence of relapse seems similar or possibly less compared to what has been observed following allogeneic sibling BMT in poor-risk ALL. In various studies, some of which also included younger patients, the relapse rate following sibling BMT varied between 9\% and 34\%. ${ }^{13-19}$ Only limited data are available with respect to relapse following unrelated BMT in poor-risk ALL. No relapses were observed in $7 \mathrm{CR} 1$ patients (including 2 younger patients) reported by Sierra et al, ${ }^{25}$ and 3 of 9 younger patients were reported to have a relapse following a TCD unrelated donor BMT for CR1 $\mathrm{Ph}^{+}$ALL. ${ }^{26}$ Recently, Arico and coworkers reported data on 326 children with $\mathrm{Ph}^{+}$ALL, including 21 who received an unrelated donor BMT, which was followed by a relapse in 4 of these 21 children. ${ }^{27} \mathrm{~A}$ possible enhanced graft-versus-leukemia (GVL) effect following unrelated BMT might be explained by the difference of HLA compatibility between HLA genotypically identical siblings versus unrelated donors, who are matched for $A$, $\mathrm{B}$, and DRB1. Mismatches at HLA-C, -DQB1, and -DPB1 frequently occur and may also be associated with GVHD and GVL. ${ }^{28,29}$ As many as $50 \%$ of donor and recipient pairs apparently matched for HLA-A and -B, using serologic typing methods, have one or more incompatibilities at $\mathrm{A}, \mathrm{B}$, or $\mathrm{C}$ alleles by DNA sequencing. ${ }^{28}$ Mismatches for DQB1 and DPB1 occur in approximately $80 \%$ of A, B, C, and DRB1 allele matched pairs, predominantly because of DPB mismatch due to the poor linkage disequilibrium between DQ and DP loci. ${ }^{28,30-33}$

Despite the low relapse rate observed, a more exact estimate of the GVL effect for comparison with sibling BMT cannot be given because a relatively high percentage of patients in this study died of TRM and, therefore, were not at risk for relapse. Nevertheless, our findings do indicate a strong GVL effect because relapse rates after autologous stem cell transplantation or intensive chemotherapy have been reported to exceed 50\%. . $^{12,16-18,27,34}$ Furthermore, apart from the low relapse rate as such, the GVL effect is further supported by the complete responses following donor lymphocyte infusion observed by us and others as well. ${ }^{35,36}$ Patients with $\mathrm{Ph}^{+}$ALL seem to be particularly susceptible for GVL effect, because we found significantly fewer relapses in $\mathrm{Ph}^{+}$ALL as compared to ALL patients with $\mathrm{t}(4 ; 11)$ or $\mathrm{t}(1 ; 19)$, which translated in better DFS (Table 3).

Survival in this study was mainly determined by TRM. Cumulative incidence of TRM was $61 \% \pm 9 \%$ for all patients and did not differ significantly for refractory patients versus patients in remission at the time of BMT (Figure 4). TRM in adult patients clearly exceeds TRM in children following unrelated BMT or following sibling BMT. Recent studies have shown that innovations in supportive care, such as improved prophylaxis for fungal and viral infections, as well as improved molecular techniques and criteria for HLA matching have resulted in less TRM in recent years, both following unrelated BMT and sibling donor BMT. ${ }^{29,37-39}$ However, when we evaluated whether results in this group of patients improved during a 10-year period, no such effect could be demonstrated. It may be explained by a persistent and overruling effect of time from diagnosis to BMT as an important risk factor for TRM and DFS. The median time from diagnosis to BMT was 8 months and that interval strongly affected TRM (independent from remission status), but not relapse (Table 3). This increased risk for TRM may be explained by the length and intensity of the preceding chemotherapy, which may add to the risk for lethal complications after BMT. Considering the high incidence of lethal complications in patients with refractory ALL added to an already higher relapse risk, unrelated donor BMT should not be encouraged in patients with refractory ALL.

Opportunistic infections and respiratory insufficiency accounted for the majority of lethal complications. Because a minority of patients dying due to TRM suffered from severe acute or chronic GVHD, our findings suggest that an impaired immune recovery rather than GVHD put the patients at risk for severe infections. An impaired immune recovery is further supported by increased TRM in CMV-seropositive patients, whereas CMV-pneumonia as the cause of death was observed in only one patient. We recently reported that CMV may still affect TRM despite effective prevention of CMV disease. This effect seems selectively to occur in severe immunocompromised patients, such as elderly patients, or patients receiving TCD grafts. ${ }^{40}$

How can the relatively high TRM be improved? The different prognostic variables associated with TRM clearly indicate that reduction of TRM may follow upon reduction in the interval between diagnosis and transplant and avoid cumulative toxicity of successive cytotoxic agents. The latter aim may very well be achieved by incorporating relatively less toxic and highly active new agents such as the novel tyrosine kinase inhibitor $\mathrm{STI}^{41}$ in induction therapy for patients with $\mathrm{Ph}^{+}$ALL. In addition, donor searches should start early to be able to perform BMT shortly after achieving remission. Furthermore, as reported before, we observed less TRM in patients receiving larger stem cell grafts. Therefore, increasing the cell dose, which may enhance neutrophil and lymphocyte recovery, ${ }^{42}$ may further reduce the susceptibility for opportunistic infections in this category of patients.

In conclusion, despite a relatively high incidence of lethal opportunistic infections and pulmonary complications, survival following unrelated donor BMT in poor-risk ALL patients in CR1 is encouraging and compares favorably to results obtained following intensive chemotherapy or autologous transplantation (or both) due to an apparently strong GVL effect. Immediate donor search and careful timing of transplantation directly upon achieving remission as well as procuring larger stem cell grafts, from fully HLA-matched donors, may further improve the outcome of unrelated donor BMT in poor-risk ALL.

\section{Acknowledgments}

The authors thank the patients, donors, transplant and donor centers, and physicians, staff, and data managers who participate in the NMDP. Janine Vrij is acknowledged for secretarial assistance. 


\section{References}

1. Hoelzer D. Therapy and prognostic factors in adult acute lymphoblastic leukaemia In: Caen J, Hershko C, Hirsh J, et al., eds. Ballière's Clinical Haematology, International Practice and Research: Acute Lymphoblastic Leukaemia. London: Ballière Tindall; 1994:299-320.

2. Copelan EA, McGuire EA. The biology and treatment of acute lymphoblastic leukemia in adults. Blood. 1995;85:1151-1168.

3. Cortes JE, Kantarjian HM. Acute lymphoblastic leukemia. A comprehensive review with emphasis on biology and therapy. Cancer. 1995;76:23932417.

4. Hoelzer D, Thiel E, Löffler H, et al. Prognostic factors in multicenter study for treatment of acute lymphoblastic leukemia in adults. Blood. 1988;71: 123-131.

5. Larson RA, Dodge RK, Burns CP, et al. A fivedrug remission induction regimen with intensive consolidation for adults with acute lymphoblastic leukemia: Cancer and Leukemia Group B study 8811. Blood. 1995;85:2025-2037.

6. Dekker AW, Van 't Veer MB, Sizoo W, et al. Intensive postremission chemotherapy without maintenance therapy in adults with acute lymphoblastic leukemia. J Clin Oncol. 1997:15:476-482.

7. Boucheix C, David B, Sebban C, et al. Immunophenotype of adult acute lymphoblastic leukemia, clinical parameters, and outcome: an analysis of a prospective trial including 562 tested patients (LALA87). Blood. 1994;84:1603-1612.

8. Groupe Francais de Cytogenétique Hématologique. Cytogenetic abnormalities in adult acute lymphoblastic leukemia: correlations with hematologic findings and outcome. A collaborative study of the Groupe Francais de Cytogénetique Hématologique. Blood. 1996;87:3135-3142.

9. Hoelzer D, Thiel E, Ludwig WD, et al. The German multicentric trials for treatment of acute lymphoblastic leukemia in adults. Leukemia. 1992;6: 175-177.

10. Fière $D$, Lepage $E$, Sebban $C$, et al. Adult acute lymphoblastic leukemia: a multicentric randomized trial testing bone marrow transplantation as postremission therapy. J Clin Oncol. 1993;11: 1990-2001.

11. Secker-Walker LM, Prentice HG, Durrant J, Richards S, Hall E, Harrison G. Cytogenetics adds independent prognostic information in adults with acute lymphoblastic leukemia on MRC trial UKALL XA. Br J Haematol. 1997;96:601-610.

12. Preti $H, O$ 'Brien $D$, Giralt $D$, et al. Philadelphiachromosome-positive adult acute lymphocytic leukemia: characteristics, treatment results, and prognosis in 41 patients. Am J Med. 1994;97: 60-65.

13. Barret J, Horowitz MM, Ash RC, et al. Bone marrow transplantation for Philadelphia chromosome-positive acute lymphoblastic leukemia. Blood. 1992;79:3067-3070.

14. Chao NJ, Forman SJ, Schmidt GM, et al. Allogeneic bone marrow transplantation for high-risk acute lymphoblastic leukemia during first complete remission. Blood. 1991;78:1923-1927.

15. Chao NJ, Blume KG, Forman SJ, et al. Long-term follow-up of allogeneic bone marrow recipients for
Philadelphia chromosome-positive acute lymphoblastic leukemia. Blood. 1995;85:3353-3354.

16. Stockschläder M, Hegewisch-Becker B, Krüger W, et al. Bone marrow transplantation for Philadelphia-chromosome-positive acute lymphoblastic leukemia Bone Marrow Transplant. 1995:16: 663-667.

17. Dunlop LC, Powles R, Singhal S, et al. Bone marrow transplantation for Philadelphia chromosome-positive acute lymphoblastic leukemia. Bone Marrow Transplant. 1996;17:365-369.

18. Grigg AP. Approaches to the treatment of Philadelphia-positive acute lymphoblastic leukemia. Bone Marrow Transplant. 1993;12:431-435.

19. Snyder DS, Nademanee AP, O'Donnell MR, et al. Long-term follow-up of 23 patients with Philadelphia chromosome-positive acute lymphoblastic leukemia treated with allogeneic bone marrow transplant in first complete remission. Leukemia. 1999;13:2053-2058.

20. Kernan NA, Bartsch G, Ash RC, et al. Analysis of 462 transplantations from unrelated donors facilitated by the national marrow donor program. N Engl J Med. 1993;328:593-602.

21. Sierra J, Storer B, Hansen JH, et al. Transplantation of marrow cells from unrelated donors for treatment of high-risk acute leukemia: the effect of leukemic burden, donor HLA-matching and marrow cell dose. Blood. 1997;89:4226-4235.

22. Przepiorka D, Weisdorf D, Martin P, et al. 1994 consensus conference on acute GVHD grading Bone Marrow Transplant. 1995;15:825-829.

23. Clift R, Goldman J, Gratwohl A, Horowitz M. Proposals for standardized reporting of results of bone marrow transplantation for leukemia. Bone Marrow Transplant. 1989:4:445-451.

24. Gooley TA, Leisenring W, Crowley J, Storer BE. Estimation of failure probabilities in the presence of competing risks: new representations of old estimators. Stat Med. 1999;18:695-706.

25. Sierra J, Radich J, Hansen JA, et al. Marrow transplants from unrelated donors for treatment of Philadelphia chromosome-positive acute lymphoblastic leukemia. Blood. 1997;90:1410-1414.

26. Marks DI, Bird JM, Cornish JM, et al. Unrelated donor bone marrow transplantation for children and adolescents with Philadelphia-positive acute lymphoblastic leukemia. J Clin Oncol. 1998;16: 931-936.

27. Arico M, Grazia Valsecchi M, Camitta B, et al. Outcome of treatment in children with Philadelphia chromosome-positive acute lymphoblastic leukemia. N Engl J Med. 2000;342:998-1006.

28. Petersdorf EW, Gooley TA, Anasetti C, et al. Optimizing outcome after unrelated marrow transplantation by comprehensive matching of HLA class I and II alleles in the donor and recipient. Blood. 1998;92:3515-3520.

29. Sasazuki T, Juji T, Morishima Y, et al. Effect of matching of class I HLA alleles on clinical outcome after transplantation of hematopoietic stem cells from an unrelated donor. Japan Marrow Donor Program. N Engl J Med. 1998;339:1177-1185.

30. Oudshoorn M, Cornelissen JJ, Fibbe WE, et al. Problems and possible solutions in finding an un- related bone marrrow donor. Results of consecutive searches for 240 Dutch patients. Bone Marrow Transplant. 1997;20:1011-1017.

31. Petersdorf EW, Mickelson EM, Anasetti C, Martin PJ, Woolfrey AE, Hansen JA. Effect of HLA mismatches on the outcome of hematopoietic transplants. Curr Opin Immunol. 1999;11:521-526.

32. Hurley CK, Baxter-Lowe LA, Begovich AB, et al. The extent of HLA class II allele level dispirarity in unrelated bone marrow transplantation: analysis of 1259 National Marrow Donor Program donorrecipient pairs. Bone Marrow Transplant. 2000; 25:385-393.

33. Santamaria P, Reinsmoen NL, Lindstrom AL, et al. Frequent HLA class I and DP sequence mismatches in serologically (HLA-A, HLA-B, HLADR) and molecularly (HLA-DRB1, HLA-DQA1, HLA-DQB1) HLA identical unrelated bone marrow transplant pairs. Blood. 1994:83:280-287.

34. Annino L, Ferrarri A, Cedrone M, et al. Adult Philadelphia-chromosome-positive acute lymphoblastic leukemia: experience of treatments during a ten-year period. Leukemia. 1994;4:664-667.

35. Yazaki M, Andoh M, Ito T, Ohno T, Wada Y. Successful prevention of hematological relapse for a patient with Philadelphia chromosome-positive acute lymphoblastic leukemia after allogeneic bone marrow transplantation by donor leucocyte infusion. Bone Marrow Transplant 1997;19:392394.

36. Keil, F, Kahls P, Haas OA, et al. Relapse of Philadelphia chromosome positive acute lymphoblastic leukemia after marrow transplantation: sustained molecular remission after early and doseescalating infusion of donor leucocytes. $\mathrm{Br} \mathrm{J}$ Haematol. 1997;97:161-164.

37. Goodrich JM, Mori M, Gleayes CA, et al. Early treatment with ganciclovir to prevent cytomegalovirus disease after allogeneic bone marrow transplantation. N Engl J Med. 1991;325:1601-1607.

38. Slavin MA, Osborne B, Adams R, et al. Efficacy and safety of fluconazole prophylaxis for fungal infections after marrow transplantation-a prospective, randomized, double-blind study. J Infect Dis. 1995;171:1545-1552.

39. Frassoni F, Labopin M, Gluckman E, et al. Results of allogeneic bone marrow transplantation for acute leukemia have improved in Europe with time-a report of the Acute Leukemia Working Party of the European Group for Blood and Marrow Transplantation (EBMT). Bone Marrow Transplant. 1996:17:13-18.

40. Broers AEC, Van der Holt R, Van Esser JWJ, et al. Increased transplant-related morbidity and mortality in CMV-seropositive patients despite highly effective prevention of CMV disease after allogeneic T-cell-depleted stem cell transplantation. Blood. 2000;95:2240-2245.

41. Druker BJ, Lydon NB. Lessons learned from the development of an Abl tyrosine kinase inhibitor for chronic myelogenous leukemia. J Clin Invest. 2000;105:3-7.

42. Ringden O, Remberger M, Runde V, et al. Peripheral blood stem cell transplantation from unrelated donors: a comparison with marrow transplantation. Blood. 1999;94:455-464. 